\title{
Ambiente Organizacional: o estudo de caso de uma Secretaria de Desenvolvimento Econômico
}

\author{
Edianne de Oliveira Farias* \\ Lígia Maria HeinzmanN**
}

\begin{abstract}
RESUMO
A pesquisa teve como objetivo analisar os fatores que influenciam o clima organizacional no ambiente de trabalho. De natureza descritiva, com abordagem qualitativa, a coleta de dados foi por meio de questionário composto por 42 questões. Com base no modelo de Rizzatti (1995) e respondido por 94 funcionários da Secretaria de Desenvolvimento Econômico do Estado de Mato Grosso, sendo realizada a análise em separado dos servidores efetivos dos ocupantes dos demais cargos. Os principais resultados foram: os fatores imagem e avaliação institucional; desenvolvimento de recursos humanos, benefícios e incentivos; organização e condições de trabalho; sucessão político-administrativa e comportamento das chefias; e satisfação pessoal influenciaram desfavoravelmente para o clima organizacional da Secretaria, por outro lado, verificou-se que o fator relacionamento interpessoal influenciou na harmonização do ambiente de trabalho. Foram propostas algumas ações para mitigar os pontos negativos e sugestões de melhorias para o clima organizacional.

Palavras-chave: Clima organizacional. Ambiente de trabalho. Cultura organizacional.
\end{abstract}

\section{Organizational ENVIRONMENT: THE CASE STUDY OF THE ECONOMIC DeVElopMent SeCRETARIAT}

\begin{abstract}
The research had as objective to analyze the factors that influence the organizational climate in the work environment. The descriptive nature, approach qualitative, data collection through the questionnaire composed of 42 questions. Based on the model of Rizzatti (1995) and answered for 94 employees that Economic Development Secretariat of the State of Mato Grosso, the analysis was performed separately from the permanent employees of the occupants of the other positions. The main results were: the image factors and institutional evaluation; human resource development, benefits and incentives; organization and working conditions; political-administrative succession and leadership behavior; and personal satisfaction unfavorably influenced favorably to the organizational climate of Secretariat, on the other hand, it was found that the interpersonal relationship factor influenced the harmonization of the work environ-
\end{abstract}

* Secretaria de Desenvolvimento Econômico. Cuiabá-Mato Grosso. Graduada em Administração pela Universidade Federal de Mato Grosso (UFMT). E-mail: ediannefarias@hotmail.com .

** Universidade Federal da Integração Latino-Americana (UNILA). Pós-doutorado em Administração pela Universidade Federal de Uberlândia (UFU)Doutora em Ciências Contábeis e Administração pela FURB. E-mail: ligiamhz@hotmail.com . 
ment. Were proposed some actions to mitigate the negative points and suggestions for improvement to the organizational climate.

Keywords: Organizational climate. Organizational environment. Organizational culture.

\section{INTRODUÇÃo}

Nos estudos de Gestão de Pessoas observa-se um tema importante dentro das organizações que é o clima organizacional, este afeta as relações internas e externas, sendo as primeiras entre os funcionários e a segunda no trato com os agentes externos, como fornecedores, clientes e parceiros.

O clima organizacional é estudado para entender como o ambiente interno reflete no grau de satisfação dos funcionários em relação à organização. Nas organizações privadas o clima organizacional está ligado com o índice de motivação de seus funcionários, por isso existem pesquisas a fim de mapear e apurar os fatores positivos e negativos que influenciam o clima organizacional.

Os estudos sobre clima organizacional favorecem a comunicação entre os funcionários e os gestores, pois buscam ouvir as opiniões e os anseios dos trabalhadores. O objetivo é melhorar o ambiente de trabalho para que os funcionários contribuam para a organização tornar-se mais produtiva e competitiva.

Para a elaboração deste estudo verificou-se trabalhos sobre clima organizacional direcionados a administração pública, alguns deles: Curvo e Heinzmann (2017) que a analisaram o clima organizacional de uma Secretaria de Gestão de Pessoas de uma Universidade Federal, utilizaram uma adaptação do Modelo de Rizzatti (1995); Sanches e Castro (1995) analisaram a percepção sobre o clima organizacional dos servidores do setor de obras da Prefeitura de Tamboara-PR, utilizaram a Escala de Clima Organizacional (ECO) de Martins (2008); Heinzmann e Silva (2014) analisaram o clima organizacional em uma Autarquia Estadual, utilizaram uma adaptação do Modelo de Luz (1996); Rocha; Ceretta e Lima (2014) analisaram o clima organizacional no âmbito de uma gestão administrativa do Hospital Regional do Sudoeste do Paraná, utilizaram a Escala de Clima Organizacional (ECO) de Martins (2008).

Neste sentido, a pesquisa tem como alvo de análise o clima organizacional em um órgão público e busca responder a indagação: Quais os fatores que influenciam o Clima Organizacional da Secretaria de Estado de Desenvolvimento Econômico (SEDEC/MT)?

Sendo assim, conhecer o grau de satisfação, as necessidades, aspirações e expectativas do servidor público constitui-se em uma importante ferramenta para melhorar o ambiente de trabalho, consequentemente aprimorar a qualidade dos serviços prestados. Nesse contexto, a avaliação do clima permite à organização a criação de um ambiente que satisfaça às necessidades de seus funcionários, ao mesmo tempo em que canaliza esse comportamento motivador na direção dos objetivos organizacionais (KOLB, 1986).

O presente estudo tem como objetivo geral analisar os fatores que influenciam o clima organizacional no ambiente de trabalho da SEDEC, e como objetivos específicos 
identificar quais os fatores que influenciam o clima organizacional; verificar como se encontra o clima organizacional com base no modelo de Rizzatti (1995); e propor ações de melhoria para o clima organizacional. Por meio do mapeamento do clima organizacional o gestor poderá direcionar esforços para os principais focos de problemas e melhorar o ambiente de trabalho.

Acredita-se que o trabalho contribuirá para o avanço e a disseminação do conhecimento científico sobre temática na área dos estudos organizacionais, a partir do levantamento bibliográfico com observância a modelos apresentados na literatura e com análise de qual o modelo mais adequado para uma organização pública.

Na prática, essa pesquisa fornecerá aos gestores da organização estudada, dados e informações sobre o ambiente de trabalho, sobre os aspectos do clima organizacional e poderá auxiliar em um processo de tomada de decisões e no planejamento de ações voltadas para a gestão de pessoas da organização. Sendo que estas ações poderão ser direcionadas para minimizar ou potencializar os fatores de clima organizacional.

A relevância social deste trabalho está relacionada à qualidade do serviço prestado pela Secretaria de Estado de Desenvolvimento Econômico, assim sendo tem-se a expectativa que os usuários dos seus serviços e a sociedade sejam beneficiados. Acredita-se que a satisfação dos servidores no ambiente de trabalho reflete no atendimento diferenciado do seu público, da mesma forma que ao estarem insatisfeitos possam externar uma má prestação de serviços.

\section{Marco teórico}

Neste referencial são apresentadas abordagens sobre o clima organizacional e alguns modelos de distintos autores sobre a temática e também uma breve abordagem sobre cultura organizacional.

\subsection{Abordagens sobre o clima organizacional}

O Clima Organizacional é um tema pouco abordado nas organizações públicas, apesar de ser um assunto muito tratado nas empresas privadas, acredita-se que o principal fator para o sucesso de uma organização são as pessoas, portanto, também é necessário pesquisas sobre a temática em organizações públicas.

Ao abordar o tema gestão de pessoas, um aspecto que deve ser considerado é o clima organizacional, que proporciona verificar como os funcionários enxergam o ambiente interno da organização, resultante da cultura da organização podendo refletir aspectos positivos ou negativos (LUZ, 1995).

Para Bennis (1996, p. 6), "clima significa um conjunto de valores ou atitudes que afetam a maneira pela qual as pessoas se relacionam uma com as outras, tais como: sinceridade, padrões de autoridade, relações sociais, etc". Neste sentido, Rizzatti (2002, p. 20) define que o "clima organizacional é considerado um conjunto de características que descrevem uma organização, considerado um conjunto de fatores, valores ou atitudes que 
afeta o relacionamento das pessoas ou, ainda, um fenômeno resultante dos elementos da cultura". Os autores mencionados relacionam o clima organizacional com as interações que o indivíduo estabelece no ambiente de trabalho, influenciando na imagem que eles têm da organização.

Enquanto, Coda (1993) entende que o grau de satisfação dos membros da empresa tem relação com o clima organizacional, isso porque cada indivíduo pode ou não, se identificar com as características adotadas pela organização, como a política de $\mathrm{RH}$, modelo de gestão, missão da empresa, processo de comunicação, valorização profissional.

Para colaborar, Luz (2003) aborda aspectos das necessidades individuais para conceituar clima como nível de satisfação material e emocional que o trabalho proporciona. Sendo que a produtividade é influenciada por este estado de satisfação do trabalhador, mas para que isso se torne favorável para a organização, o colaborador deve se sentir motivado, além da boa relação entre os funcionários e a organização.

Rizzatti (2002) defende a questão do clima organizacional como uma responsabilidade de todos os departamentos da instituição e não de um único indivíduo, sendo que o esforço de todos que contribui para melhoria do clima. O clima organizacional aprofunda o entendimento de como os membros da organização se sentem diante das atitudes e ações desenvolvidas pela organização, isso pode levar os indivíduos a se sentirem satisfeitos ou insatisfeitos dentro da instituição.

Oportunamente, Zanelli (2004) explica que as pessoas dentro de uma organização se movem e se animam em função da visão construída pelos seus dirigentes, fundadores, ou seja, é o espírito desenvolvido pela alta diretoria que reflete no modo de pensar e agir dos membros de uma organização.

Para Rizzatti (2002) a análise do clima serve para a organização identificar onde se situam as grandes deficiências e dispender esforços para solucioná-las, fazendo com que o colaborador se sinta integrado dos objetivos e metas da empresa, contribuindo para melhorar o desempenho pessoal e profissional do indivíduo na organização.

Portanto, as abordagens apresentadas pelos autores demonstram que a percepção de clima organizacional é subjetiva, pois depende da visão de cada indivíduo, e estes têm anseios, interesse e necessidades distintas de seus pares.

O ambiente organizacional que estabelece se o indivíduo vai dispor de toda sua capacidade de desempenho em favor dos objetivos da organização, porém com a condição de que a estrutura organizacional vai lhe propiciar para realizar suas necessidades.

Os autores abordam fatores que podem influenciar no ambiente de trabalho, podendo estes se complementarem e levando em consideração o contexto social das organizações. Esse conjunto de fatores é conhecido como modelo de clima organizacional. $\mathrm{Na}$ sequência são apresentados alguns modelos. 


\subsection{Modelos de Clima Organizacional}

\subsubsection{Modelo de Litwin e Stringer (1968)}

O modelo elaborado por Litwin e Stringer (1968 apud BARTHASAR, 2014, p. 35) apresenta a análise de clima organizacional a partir de 09 fatores, sendo: 1) Estrutura trata-se das regras, regulamentos e procedimentos; 2) Responsabilidade é a autonomia para tomada de decisão; 3) Desafio é o quanto o empregado está disposto a arriscar no cargo e no trabalho; 4) Recompensa é consequência de um trabalho bem realizado; 5) Relacionamento está relacionado com ajuda mutua que prevalece na organização; 6) Cooperação é o espírito de cooperar, o trabalho em equipe; 7) Conflito diz respeito como a administração aceita as diferentes opiniões e trata os conflitos; 8) Identidade é o sentimento de pertencer a organização, como membro valioso e importante e 9) Padrões representa o grau em que a organização enfatiza normas e processos.

\subsubsection{Modelo de Sbragia (1983)}

O Modelo abordado por Sbragia (1983 apud BARTHASAR, 2014, p. 37) identifica 20 fatores que influenciam o clima organizacional: 1) Estado de tensão descreve que a lógica e racionalidade regem as ações das pessoas; 2) Conformidade exigida reflete o quanto a organização conscientiza a necessidade de obediência a normas e regulamentos formais; 3) Ênfase na participação refere-se ao envolvimento das pessoas nas decisões, ou seja, o quanto suas ideias e sugestões são aceitas; 4) Proximidade da supervisão é as pessoas terem liberdade para fixar seus métodos de trabalho, é o quanto as pessoas têm possibilidade de exercitar a iniciativa; 5) Consideração humana descreve o quanto as pessoas são tratadas como seres humanos; 6) Adequação da estrutura é o esquema organizacional para facilitar as ações das pessoas e o quanto existe na prática, normas, procedimentos e canais de comunicação consistentes com os requisitos de trabalho; 7) Autonomia presente é o quanto as pessoas se sentem com seus próprios patrões e não precisam ter suas decisões verificadas.

Demais fatores, 8) Recompensas proporcionais reflete o quão bem as pessoas são recompensadas pelo trabalho que fazem; o quanto de ênfase é dado em recompensas positivas em vez de punições; o quanto é justa a política de pagamento e promoções; 9) Prestígio obtido é a percepção das pessoas sobre sua imagem no ambiente externo pelo fato de pertencerem a organização; 10) Cooperação existente trata da amizade e das boas relações sociais que prevalecem na atmosfera de trabalho da organização. 11) Padrões enfatizados dizem respeito à ênfase dada à realização de um bom trabalho; 12) Atitude frente a conflitos é a relevância dada pelas pessoas em "levantar o problema" antes de ignorá-lo; 13) Sentimento de identidade descreve o quanto as pessoas dão valor à organização da qual fazem parte; 14) Tolerância existente representa o grau com que os erros das pessoas são tratados de forma suportável e construtiva antes do que punitiva; 15) Clareza percebida significa o grau de conhecimento das pessoas relativamente aos assuntos que lhes dizem respeito; 16) Justiça predominante reflete o grau com que as habilidades e desempenhos predominam nos critérios de decisão antes do que aspectos políticos, pessoais ou credenciais; 17) Condições de progresso é a organização proporcionar a seus membros oportunidade de 
crescimento e avanço profissional; 18) Apoio logístico proporcionado são as condições e os instrumentos de trabalho necessários para um bom desempenho; 19) Reconhecimento proporcionado é o quanto a organização valoriza um desempenho ou uma atuação acima do padrão por parte de seus membros; o quanto os esforços individuais diferenciados são reconhecidos; 20) Forma de controle são os dados de controle utilizados pela organização para efeito de auto orientação e solução de problemas antes do que para policiamento e castigo.

\subsubsection{Modelo de Kolb, Rubin e MCIntyre (1986)}

Foi elaborado com base nos estudos de Litwin e Stringer e era um instrumento de aprendizagem para exercícios em classe. Utiliza uma escala de 07 fatores de clima (KOLB et al., 1986 apud RIZZATTI, 2002, p. 34).

O Primeiro, 1) Conformismo é o sentimento de que existem muitas limitações externamente impostas na organização; o grau em que os membros sentem que há inúmeras regras, procedimentos, políticas e práticas às quais devem se amoldar ao invés de serem capazes de fazer seu trabalho como gostariam de fazê-lo; 2) Responsabilidade descreve o grau em que os membros sentem que podem tomar decisões e resolver problemas sem terem de verificar com os superiores cada etapa; 3 ) Padrões é a ênfase que a organização coloca na qualidade do desempenho e na produção elevada, incluindo o grau em que os membros da organização sentem que ela coloca objetivos estimulantes, comunicando-lhes o comprometimento com esses objetivos; 4) Recompensas representa o grau que os membros sentem que estão sendo reconhecidos e recompensados por um bom trabalho, ao invés de serem ignorados, criticados ou punidos quando algo sai errado; 5) Clareza organizacional é o sentimento, entre os membros, de que as coisas são bem organizadas e os objetivos claramente definidos, ao invés de serem desordenados, confusos ou caóticos; 6) Calor e apoio versam sobre o sentimento de que a amizade é uma forma valorizada na organização, onde os membros confiam uns nos outros e oferecem apoio mútuo. Os sentimentos de boas relações prevalecem no ambiente de trabalho; 7) Liderança trata da disposição dos membros da organização para aceitar a liderança e a direção de outros qualificados. Quando surgem as necessidades de liderança os membros sentem-se livres para assumi-la e são recompensados por uma liderança bem sucedida.

\subsubsection{Modelo de Luz (1995)}

Luz (1995) apresenta um modelo de questionário de pesquisa de clima organizacional o qual possui 18 variáveis ou fatores. O 1) trabalho em si refere-se ao conhecimento da percepção e atitude das pessoas em relação ao trabalho que executam; 2) Integração interdepartamental/ integração funcional busca avaliar o grau de cooperação existente entre os diversos departamentos da organização; 3) Salário verifica a existência de eventuais distorções entre os salários internos e eventuais descontentamentos em ralação aos praticados no mercado; 4) Supervisão mensura o grau de satisfação dos funcionários em relação aos supervisores, analisando a competência, organização, relacionamento e feedback; 5) Comunicação descreve o grau de conhecimento dos funcionários em relação a fatos rele- 
vantes da empresa; 6) Progresso profissional identifica as oportunidades de treinamento e possibilidades de ascensão profissional.

O sétimo fator é o 7) Relacionamento Interpessoal descreve o grau de relacionamento que prevalece entre os funcionários, entre estes e sua chefia e com a própria organização; 8) Estabilidade no emprego refere-se ao sentimento de segurança das pessoas em relação aos seus empregos; 9) Processo decisório identifica o grau de autonomia do funcionário, bem como o grau de centralização das decisões; 10) Benefícios verifica o grau de satisfação com relação aos diversos benefícios oferecidos pela empresa; 11) Condições físicas de trabalho identificação do grau de conforto das instalações da organização; 12) Relacionamento empresa $\mathrm{x}$ sindicato $\mathrm{x}$ funcionários avalia o sentimento de atendimento às queixas e reclamações dos funcionários bem como o grau de satisfação dos mesmos em relação ao sindicato.

Os demais fatores, 13) Disciplina que demonstra o grau de rigidez das normas disciplinares e o nível de insatisfação gerado por elas; 14) Participação identifica o grau de participação na gestão administrativa da empresa; 15) Pagamento refere-se o nível de conhecimento dos funcionários em relação aos descontos efetuados e aos erros indevidos por ocasião do pagamento; 16) Segurança diz respeito a preocupação da organização e as providencias tomadas em relação à integridade física da sua força de trabalho, no que se refere a acidentes de trabalho e doenças ocupacionais; 17) Objetivos organizacionais evidencia a clareza da comunicação, aos funcionários, dos objetivos e planos de ação nos níveis setorial e organizacional; 18) Orientação para resultados avalia até que ponto a empresa estimula sua força de trabalho para que os funcionários se comprometam pela consecução de resultados.

\subsubsection{Modelo de Rizzatti (1995)}

Com base nos modelos sugeridos, Rizzatti propôs em 1995 um modelo pertinente a ser utilizado em organizações públicas de ensino, no qual considerou seis fatores ou variáveis:

1. Imagem e avaliação institucional, imagem é o prestígio que desfruta uma organização, tendo uma imagem pública favorável ou não favorável. Dressel (1995 apud RIZZATTI) entende avaliação por um processo completo, sistemático e contínuo que conduz uma organização a melhoria da qualidade, assegurando uma imagem positiva perante a sociedade;

2. Desenvolvimento de recursos humanos, benefícios e incentivos, para Rizzatti (1995) a função do desenvolvimento é estimular o trabalhador a assumir responsabilidades, enquanto o benefício seria uma complementação legal ou assistencial, que só deveria ser ofertada caso a organização consiga dar continuidade ao programa. Já os incentivos atuam como um estimulante para elevar o ego do trabalhador, conduzindo a produzir melhor e mais satisfeito;

3. Organização e condições de trabalho, a organização condiz em atividades coordenadas, planejadas, com divisão de trabalho entre uma ou mais pessoas afins de atingir objetivos comuns de uma equipe. Condições de trabalho é o ambiente organizacional favorável para desenvolver as atividades, com alto nível de rendimento dos funcionários, proporcionando atender algumas de suas necessidades; 
4. Relacionamento interpessoal, de acordo com o autor relacionamento interpessoal é interação ou relação entre duas ou mais pessoas ou sistema de qualquer natureza, onde um depende da atividade desenvolvida pelo outro, há uma reciprocidade, surgindo sentimentos que influenciam nos processos mentais e emocionais, que são implícitos. Só são percebidos por pessoas que desfrutam da mesma interação.

5. Sucessão político-administrativa e comportamento das chefias, segundo Vahl (1991, apud RIZZATTI, 1995, p. 30) "a sucessão político-administrativa é o mecanismo utilizado para designar as chefias, através do processo indicativo ou eletivo, observando normas específicas instituídas na organização". Para o autor do modelo, o chefe precisa ser dotado de algumas características, como noção das funções gerais da instituição, inteligência, qualidades morais (caráter), lealdade, equidade, decisão, capacidade para delegar competência, capacidade de cooperar, entre outras. Ainda completa, que cada chefe tem um comportamento e um estilo próprio de comandar, de acordo com sua personalidade ou ambiente de trabalho, conduzindo a diferentes climas organizacionais.

6. Satisfação pessoal, significa o quanto o trabalhador está contente com as atividades que exercem e o reconhecimento por parte da organização. É importante destacar que o reconhecimento ou recompensa é aquela que indivíduo julga ser compatível com seu nível de esforço, por isso manter o funcionário satisfeito é um trabalho árduo, com afirma Rizzatti (1995), pois se trata de necessidades individuais, que podem ser percebidas na análise de clima organizacional.

\subsubsection{Modelo de Coda (1997)}

Coda (1997 apud BARTHASAR, 2014, p. 40) realizou um estudo sobre o tema motivação e liderança organizacional em cinco diferentes organizações brasileiras de grande porte do setor público e privado, apresentando o modelo de clima organizacional levando em consideração 10 fatores.

O primeiro fator é a 1) Liderança que descreve o grau de influência gerado pela chefia sobre seus subordinados; 2) Compensação consiste no balanceamento das diferentes formas de remuneração adotadas pela empresa, amplitude de benefícios, concessão de aumentos por desempenho e realização de metas; 3) Maturidade empresarial é a compreensão adequada pelos membros da organização sobre pressão exercida pelo mercado, concorrentes e dos clientes; 4) Colaboração entre áreas funcionais refere-se ao respeito e integridade entre as diferentes áreas funcionais para atingir os objetivos da empresa; 5) Valorização profissional é o estimulo a formação e ao desenvolvimento de talentos internos; oportunidades de crescimento e avanço profissionais oferecidas; 6) Identificação com a empresa representa a motivação da equipe e busca de objetivos mútuos.

Os outros cinco fatores consistem em, 7) Processo de comunicação trata da adequação das informações recebidas ao correto desempenho das atividades, instrumento facilitador de integração da empresa; 8) Sentido de trabalho é a importância atribuída ao que 
acontece com a organização, utilidade e importância do trabalho realizado no contexto organizacional; 9) Política global de recursos humanos diz respeito ao apoio fornecido pelas políticas de RH ao desenvolvimento do trabalho, disponibilidade para ouvir e considerar diversidades de opiniões; 10) Acesso é a continuidade de realizar da mesma forma o trabalho até o final da carreira.

\subsubsection{Modelo de Rizzatti (2002)}

O modelo proposto por Rizzatti (2002) apresenta 12 fatores aplicados a instituições públicas, especificamente para tratar de clima organizacional em Universidades Públicas.

Dentre os fatores estão a 1) Imagem institucional que significa o prestígio de que desfruta uma organização; seguido da 2) Política de Recursos Humanos adotadas pelas organizações para desenvolvimento profissional e humano; depois o 3) Sistema de assistência e benefícios que são os incentivos, ações ou atitudes que na organização agem como estimulantes do ego do trabalhador; 4) Estrutura Organizacional que estabelece a hierarquia funcional entre os setores, os departamentos da organização; 5) Organização e condições de trabalho que aborda a divisão do trabalho em função e através de uma hierarquia de autoridade e responsabilidade.

O modelo traz outros fatores como o 6) Relacionamento interpessoal como sendo interação ou relação entre duas pessoas ou sistemas de qualquer natureza, de modo que a atividade de cada um está em parte determinada pela atividade do outro; 7) Comportamento das chefias para descrever as características do chefe e de seu comportamento; 8) Satisfação pessoal que engloba a satisfação dos empregados ao desempenharem suas tarefas.

Os últimos quatro fatores descrevem os processos de planejamento, decisão e avaliação da organização, como 9) Planejamento institucional que incorpora procedimentos lógicos, para facilitar as decisões; depois 10) Processo decisório que é um sistema de decisões em que cada um participa, escolhendo e decidindo entre alternativas mais ou menos racionais; por se tratar de clima em universidade trata da 11) Autonomia universitária a capacidade de se governar por leis próprias; e por último a 12) Avaliação institucional que consiste em verificar o grau de eficiência e o grau de eficácia no alcance dos objetivos organizacionais.

\subsubsection{Modelo de Bispo (2006)}

O modelo proposto por Bispo (2006) foi aplicado em duas instituições públicas, e leva em consideração 20 fatores que influenciam o clima organizacional, sendo divididos em interno e externo.

Os fatores internos seriam: 1) Ambiente de trabalho estabelece o grau de relacionamento entre os colegas de trabalho, necessário para realização das atividades individuais ou coletivas; 2) Assistência aos funcionários refere-se aos benefícios oferecidos pela organização como da assistência médica, dentária, hospitalar e social; 3) Burocracia avalia se este item está compatível com as atividades realizadas pelos funcionários; 4) Cultura organizacional diz respeito às tradições, práticas e costumes, adotados informalmente na empresa, 
exercem sobre os funcionários e suas atividades; 5) Estrutura organizacional avalia o relacionamento e a capacitação dos elementos que compõem esta estrutura e sua interferência nas atividades realizadas pelos funcionários.

Ainda são citados como fatores internos, 6) Nível sociocultural busca identificar se os níveis intelectuais, culturais e sociais dos funcionários condizem com as atividades desenvolvidas pelo funcionário; 7) Incentivos profissionais tendem a proporcionar o reconhecimento profissional dos funcionários; 8) Remuneração mede se este item está de acordo com as atividades prestadas à empresa; 9) Segurança profissional analisa o risco de demissão sem motivo percebido pelos funcionários; 10) Transporte casa/trabalho - trabalho/casa verifica se o funcionário tem dificuldade de se deslocar de sua casa a empresa e vice-versa; 11) Vida profissional tenta medir o nível de satisfação e orgulho do profissional em relação à empresa e de seu sucesso profissional.

Na segunda parte de seu estudo o autor Bispo (2006) apresenta os Fatores externos que influenciam o ambiente interno da organização, estes por surgirem fora da empresa não há como ter controle, são: 12) Convivência familiar representa a convivência familiar dos funcionários, influência na boa produtividade nas atividades realizadas na empresa; 13) Férias e lazer analisa a satisfação dos funcionários com estes itens, também são necessários para garantir uma boa produtividade; 14) Investimentos e despesas familiares busca avaliar o bem-estar proporcionado às famílias dos funcionários; 15) Política e Economia buscar entender a interferência proporcionado por estes itens na motivação dos funcionários; 16) Saúde verifica a opinião dos próprios funcionários sobre suas respectivas saúdes física e mental, apesar da importância é difícil observar; 17) Segurança Pública representa a influência deste item na vida diária dos funcionários; 18) Situação financeira tenta identificar como está a situação financeira dos funcionários; 19) Time de futebol avalia como os times de futebol exercem influência sobre a motivação e a produtividade dos funcionários; e 20) Vida social trata da satisfação dos funcionários com este item.

Além dos modelos apresentados neste artigo também foram elaborados os Modelos de Schneider (1975), Campbell et al. (1970), La Follete e Sims (1975) e Martins (2008) que elaborou a Escala do Clima Organizacional (ECO).

Após a análise dos fatores/variáveis dos modelos apresentados optou-se para este trabalho utilizar com base o Modelo de Rizzatti (1995), pois se teve o entendimento de que os seus 6 fatores contemplariam o necessário para analisar o clima organizacional na organização pública selecionada.

\subsection{Cultura organizacional}

Ao conceituar clima organizacional, alguns autores consideram que a cultura organizacional reflete no comportamento dos indivíduos de uma organização e, por conseguinte no clima. Portanto, não há como conceituar clima organizacional e não mencionar a cultura organizacional.

A autora Krumm (2013, p. 12) conceitua que, "cultura organizacional é a maneira correta de perceber, de imaginar e de sentir em uma organização". 
A cultura leva os integrantes de uma organização a se comunicarem, a se relacionarem de uma maneira particular adotada por aquela organização específica, no entanto obedecendo aos níveis hierárquicos estabelecidos (ZANELLI, 2004).

Para Rizzatti (2002, p. 19) "A cultura compreende um conjunto de propriedades do ambiente de trabalho percebido pelos empregados, constituindo-se numa das forças importantes que influenciam no comportamento". Ainda para o autor, os valores de uma organização compõem sua identidade, sua missão, orienta seus princípios, definindo sua imagem e formulando seus conceitos de qualidade que espera transmitir.

A cultura organizacional está relacionada com o pensar e agir das pessoas dentro de uma organização, segundo seus valores, costumes, hábitos, crenças, tradição. É como a organização se vê através das ações de seus integrantes.

De acordo com Schein (1985), a cultura organizacional pode ser entendida como um conjunto de pressupostos básicos criado, desenvolvido ou descoberto em um processo de aprendizagem coletivo para lidar com os problemas socioemocionais dos membros do grupo e que permite às organizações se adaptarem às demandas externas.

Deste modo a cultura orienta as ações e atitudes compartilhadas na empresa, reflete o comportamento dos indivíduos perante os valores e princípios transmitidos pela organização.

Nesse sentido a gestão de pessoas, juntamente com as ferramentas desenvolvidas por diversos estudiosos da cultura e do clima organizacional, e também da aplicação dos seus modelos tem contribuído para identificar deficiências no ambiente organizacional e auxiliado com informações para melhorar os relacionamentos interpessoais, o que tem refletido em melhor desempenho dos funcionários, e por consequência uma melhor prestação de serviços.

Assim, um dos maiores desafios para os gestores públicos, em compreender os Órgãos Públicos como uma empresa, onde é fundamental aplicar as ferramentas da administração para alcançar os resultados desejados, implantando gestão dos recursos, melhorando o planejamento e entender que a organização pública é uma instituição com ações públicas que devem ser contínuas.

\section{Procedimentos metodológicos}

Este estudo se enquadra como uma pesquisa descritiva, pois objetiva descrever as características de certa população. Para Lakatos (2007) na pesquisa descritiva, o pesquisador registra e descreve a realidade estudada, sem nela interferir.

Com relação à abordagem é qualitativa, que pode ser definida como a que se fundamenta principalmente em análises qualitativas, caracterizando-se, em princípio, pela não utilização de instrumental estatístico na análise dos dados.

$\mathrm{O}$ artigo consiste em um estudo de caso por envolver o estudo aprofundado de um objeto de maneira que permite aprimorar o conhecimento sobre o mesmo (YIN, 2001). Foi utilizado um instrumento para coleta dos dados, composto por 42 questões com base no modelo de Rizzatti (1995). Os dados foram coletados no mês de dezembro de 2017. 
A Secretaria de Estado de Desenvolvimento Econômico - SEDEC foi o órgão escolhido para desenvolver a pesquisa, sendo que a população para a pesquisa foi de 164 funcionários e a amostra foi de 94 funcionários, considerando margem de erro de $3 \% \mathrm{com}$ base no cálculo da distribuição binomial (BEZERRA, 2003).

Para a análise dos dados foram separadas as respostas dos servidores das respostas dos ocupantes dos demais cargos (comissionados, estagiários e contratados), com intuito de entender como os servidores e demais funcionários vislumbram o clima organizacional da SEDEC.

\section{ANÁlise e DISCUSSÃo dOS DADOS}

\subsection{Caracterização da Instituição Pesquisada}

A Secretaria de Estado de Desenvolvimento Econômico - SEDEC/MT, instituída pela Lei Complementar $n^{\circ} 566 / 2015$, tem a finalidade de ser a responsável por gerenciar os trabalhos de planejamento, articulação e de execução da política econômica traçada pelo Governo do Estado com o objetivo de promover o desenvolvimento socioeconômico de Mato Grosso. É formada pelas Secretarias Adjuntas de Administração Sistêmica, Indústria e Comércio, Empreendedorismo e Investimentos, Agricultura e Turismo.

A missão da SEDEC é promover o desenvolvimento socioeconômico do Estado, fomentando políticas setoriais que busquem a ampliação e manutenção dos segmentos empresariais. Sua visão é transformar Mato Grosso no Estado com melhor ambiente de negócios do país. Seus valores são legalidade, impessoalidade, moralidade, publicidade e eficiência.

\subsection{Fatores de análise}

A partir da coleta de dados foi possível analisar e entender o clima organizacional da SEDEC. O instrumento de coleta contemplou fatores como: imagem e avaliação da SEDEC; desenvolvimento de recursos humanos, benefícios e incentivos; organização e condições de trabalho; relacionamento interpessoal; sucessão político-administrativa e comportamento das chefias; e satisfação pessoal, de acordo como modelo de Rizzatti (1995).

Conforme mencionado nos procedimentos metodológicos, na adaptação do questionário se optou pela utilização da escala Likert para as 42 questões, nas quais o respondente de acordo com o seu grau de concordância ou discordância poderia marcar as seguintes opções:

- (1) nunca/(2) poucas vezes/(3) às vezes/(4) frequentemente/(5) sempre;

- (1) nada/(2) pouco/(3) razoável/(4) muito/(5) muitíssimo;

- (1) ruim/(2) pouco satisfatório/(3) regular/(4) bom/(5) ótimo. 
Das 94 respostas, 46\% foram oriundas da Secretaria Adjunta de Administração Sistêmica, seguida de 19\% da Indústria e Comércio, 13\% do Turismo, 12\% Empreendimentos e Investimentos e 10\% da Agricultura. Do total de 52\% servidores, 44\% exclusivamente comissionados, 3\% Estagiários e 1\% contratado. O perfil dos respondentes pode ser observado na Tabela 1.

Tabela 1: Perfil dos respondentes

\begin{tabular}{|c|c|c|}
\hline \multicolumn{3}{|c|}{ Perfil dos Respondentes } \\
\hline & Menos de 30 anos & $19 \%$ \\
\hline & De 30 a 39 anos & $38 \%$ \\
\hline \multirow[t]{5}{*}{ Idade } & De 40 a 49 anos & $24 \%$ \\
\hline & De 50 a 59 anos & $13 \%$ \\
\hline & Mais de 59 anos & $5 \%$ \\
\hline & Menos de 03 anos & $31 \%$ \\
\hline & De 03 a 05 anos & $26 \%$ \\
\hline \multirow[t]{3}{*}{ Tempo de Serviço } & De 06 a 10 anos & $26 \%$ \\
\hline & De 11 a 15 anos & $3 \%$ \\
\hline & Acima de 15 anos & $15 \%$ \\
\hline \multirow[t]{4}{*}{ Sexo } & Feminino & $44 \%$ \\
\hline & Masculino & $56 \%$ \\
\hline & Administração Sistêmica & $46 \%$ \\
\hline & Turismo & $13 \%$ \\
\hline \multirow[t]{4}{*}{ Lotação } & Empreendedorismo e Investimento & $12 \%$ \\
\hline & Agricultura & $11 \%$ \\
\hline & Indústria e Comércio & $19 \%$ \\
\hline & Efetivo & $52 \%$ \\
\hline \multirow[t]{3}{*}{ Cargo } & Comissionado & $44 \%$ \\
\hline & Estagiário & $3 \%$ \\
\hline & Contratado & $1 \%$ \\
\hline \multirow[t]{2}{*}{ Cargo de Chefia } & Sim & $46 \%$ \\
\hline & Não & $54 \%$ \\
\hline
\end{tabular}

Fonte: Dados da pesquisa (2017)

Optou-se por apresentar parte dos dados de forma gráfica e parte de forma descritiva, comparando as respostas dos servidores efetivos com as dos ocupantes dos demais cargos, de acordo com a ordem do instrumento e na sequência dos fatores abordados no modelo selecionado.

O primeiro fator analisado é a imagem e avaliação da SEDEC, de acordo com a pergunta: Com que frequência você associa a SEDEC, com a imagem depreciativa que se faz do serviço público na imprensa/mídia? As respostas dos servidores foram: 35\% nunca, $20 \%$ poucas vezes, $37 \%$ às vezes, $6 \%$ frequentemente e $2 \%$ sempre. As respostas apresentadas pelos demais respondentes foram: $36 \%$ nunca, $33 \%$ poucas vezes, $22 \%$ às vezes, $9 \%$ frequentemente. 
Mesmo não havendo um consenso, nota-se que a associação da imagem depreciativa do serviço público com a imagem da SEDEC, tanto na visão dos servidores quanto para os ocupantes dos demais cargos ocorre com pouca frequência, mas mesmo assim é algo que precisa ser verificado, pois significa que é possível realizar ainda algumas melhorias para que o conceito da imagem da Secretaria seja sempre positivo.



Figura 1: Servidores - Sentimento de orgulho da imagem pública da SEDEC.

Fonte: Dados da pesquisa (2017)

$\mathrm{Na}$ Figura 1, ao indagar os servidores se a imagem pública da SEDEC desperta sentimento de orgulho em você? Nota-se que não há um consenso nas respostas, $23 \%$ frequentemente, $14 \%$ sempre, $41 \%$ às vezes, $20 \%$ poucas vezes e $2 \%$ nunca.
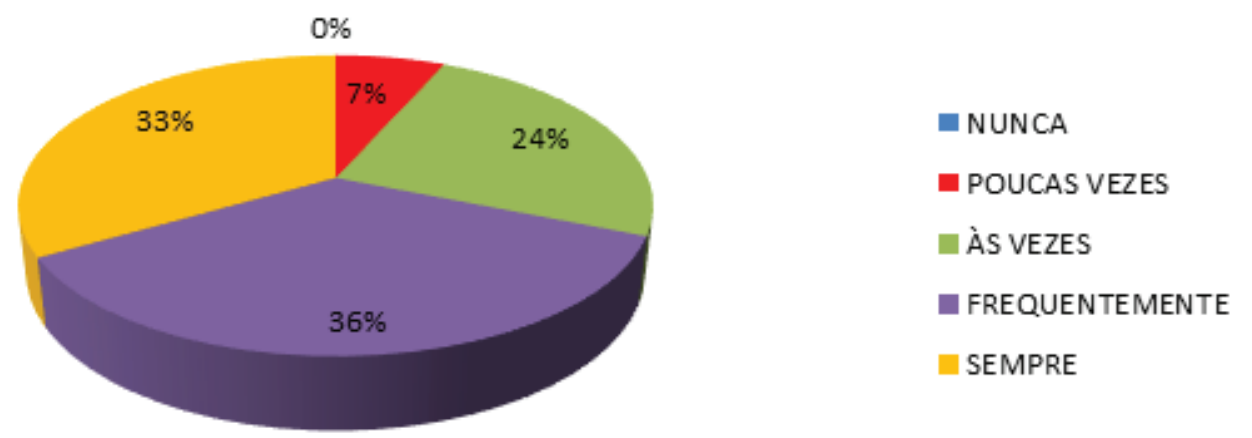

Figura 2: Demais respondentes - Sentimento de orgulho da imagem pública da SEDEC.

Fonte: Dados da pesquisa (2017)

$\mathrm{Na}$ Figura 2, observa-se que somando as respostas afirmativas, para a maioria dos demais respondentes a imagem pública da SEDEC desperta sentimento de orgulho (36\% frequentemente e $33 \%$ sempre).

Para Rizzatti (1995) a imagem é o prestígio que desfruta uma organização, tendo uma imagem pública favorável ou não favorável. Verificou-se que os servidores e demais respondentes possuem uma visão diferente da imagem da SEDEC, enquanto 69\% dos ocu- 
pantes dos demais cargos sentem orgulho da organização, por outro lado, somente $37 \%$ dos servidores demonstram esse sentimento de orgulho.

Essa variação nas respostas dos servidores é um ponto de alerta aos gestores da organização, pois pode contribuir para um clima organizacional não favorável. Devem ser investigados quais os motivos que levaram aos servidores a não se sentirem orgulhosos pela imagem da SEDEC. Podendo inclusive ser o envolvimento de gestores em escândalos que viraram manchete nos jornais, deixando a opinião pública afetar o ambiente interno da organização.

Outro fator abordado pelo autor é o desenvolvimento de recursos humanos, benefícios e incentivos, que serão analisados nos quatro próximos gráficos.

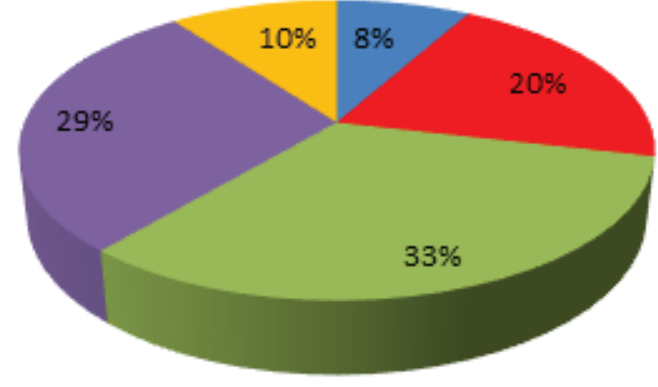

NUNCA

POUCAS VEZES

ÀS VEZES

FREQUENTEMENTE

SEMPRE

Figura 3: Servidores - A política de Recursos Humanos de valorização do servidor pelo desempenho profissional. Fonte: Dados da pesquisa (2017)

A Figura 3 demonstra a composição das respostas a indagação: Você acha que a política de Recursos Humanos da SEDEC valoriza o servidor quanto ao seu desempenho profissional? Não houve uma concordância nas respostas dos servidores, sendo que 39\% estão contentes contra $28 \%$ que estão descontentes com as políticas de valorização por desempenho profissional.

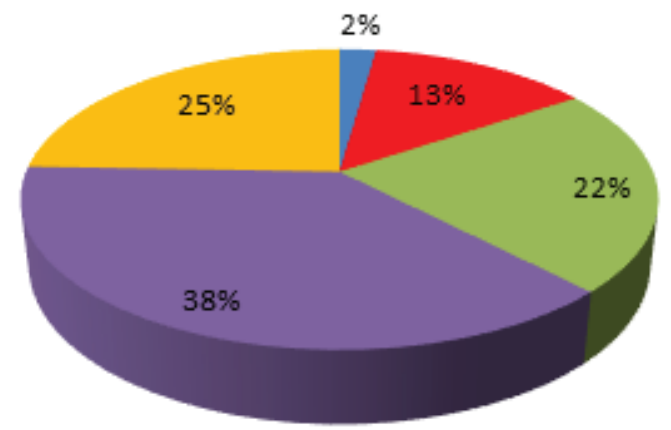

\section{NUNCA \\ POUCAS VEZES \\ ÀS VEZES \\ FREQUENTEMENTE \\ SEMPRE}

Figura 4: Demais respondentes - A política de Recursos

Humanos de valorização do servidor pelo desempenho profissional.

Fonte: Dados da pesquisa (2017) 
Por outro lado, somando as respostas afirmativas dos demais respondentes, 38\% frequentemente e $25 \%$ sempre, totalizando $63 \%$ que afirmam que a política de Recursos Humanos da SEDEC valoriza o servidor pelo desempenho profissional.

Contudo deve ser analisado pela gestão da Secretaria, pois a discordância nas opiniões pode gerar um descontentamento, podendo criar um ambiente desarmônico e desfavorável para o clima organizacional.

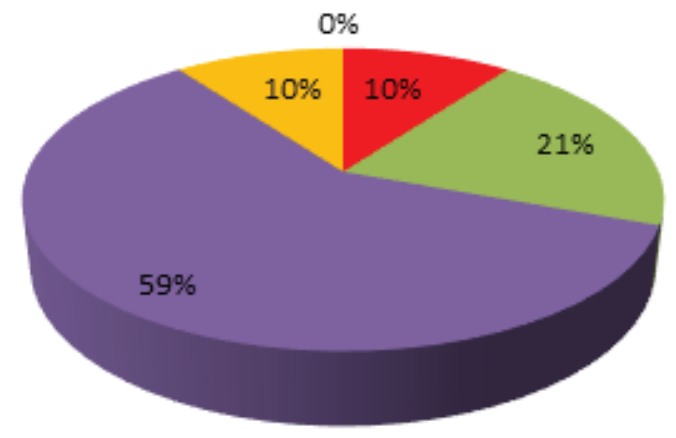

" RUIM
" POUCO SATISFATÓRIO
" REGULAR
" BOM
" ÓTIMO

Figura 5: Servidores - Compatibilidade da remuneração as atividades executadas.

Fonte: Dados da pesquisa (2017)

Ao questionar os servidores se consideram que a remuneração é compatível com as atividades que executam tendo como referencia o mercado de trabalho, $69 \%$ estão satisfeitos (bom e ótimo) com a remuneração, 21\% regular e 10\% consideram incompatível.

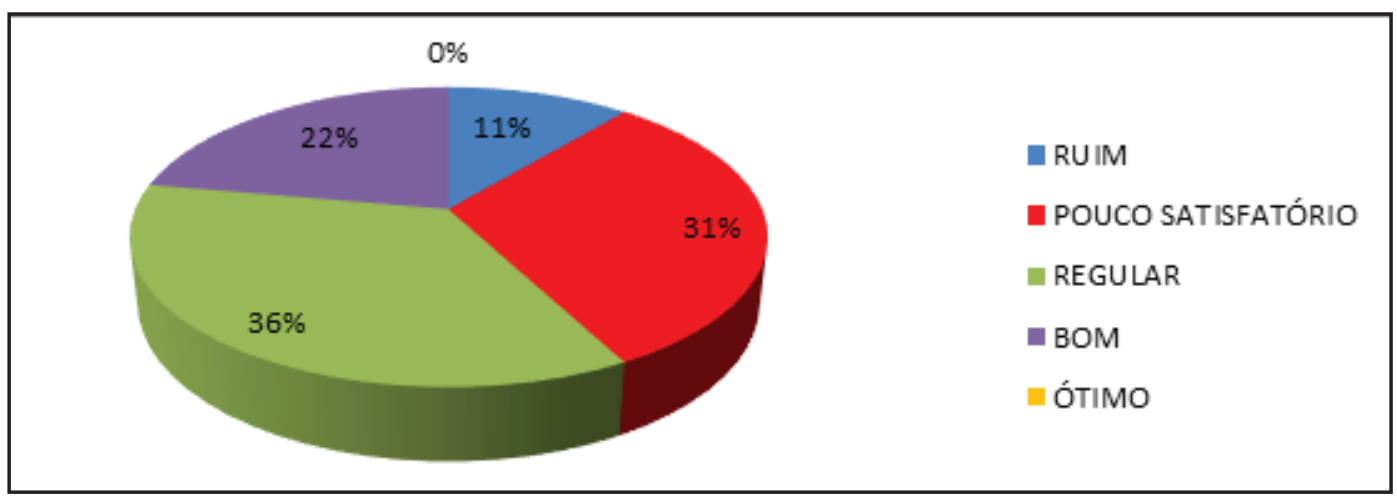

Figura 6: Demais respondentes -

Compatibilidade da remuneração as atividades executadas.

Fonte: Dados da pesquisa (2017)

Porém ao analisar as respostas dos ocupantes dos demais cargos, não há um consenso, sendo que $42 \%$ consideram incompatível, $36 \%$ regular e $22 \%$ estão satisfeitos com as remunerações.

A divergência apresentada nas respostas dos servidores em comparação com os demais respondentes pode ser explicada, pois enquanto os primeiros ao se candidatarem a 
vaga no concurso público já conhecem o plano de cargos e carreiras da vaga que estão concorrendo, sabendo os critérios para aumentar sua remuneração. Todavia isso não acontece com os ocupantes dos demais cargos, onde a maioria desses funcionários são pessoas que apoiaram políticos e como recompensa elas são encaixadas nas vagas disponíveis de seu padrinho político, o que muitas vezes é incompatível com a formação profissional e com a pretensão salarial, uma vez que estes ocupantes dos demais cargos não possuem planos de cargos e carreiras.

Por se tratar de cargo público, as remunerações são estabelecidas em lei. De acordo com Rizzatti (1995) a valorização e o reconhecimento, refletem no desempenho profissional com a função de estimular o trabalhador a assumir responsabilidades, estimular o ego do trabalhador, conduzindo a produzir mais e também mais satisfeito.

Como demonstrado, a percepção de valorização e reconhecimento dos servidores e dos ocupantes dos demais cargos são diferentes, deve-se a partir dos dados obtidos identificar o que está gerando contentamento ou frustação, para potencializar os fatores favoráveis e mitigar os fatores desfavoráveis, com intuito de manter a harmonia no ambiente de trabalho, onde se possa proporcionar a todos os sentimentos de valorização e satisfação com suas remunerações.

O terceiro fator apresentado é sobre organização e condições de trabalho, analisados a partir das Figuras 7, 8, 9 e 10.

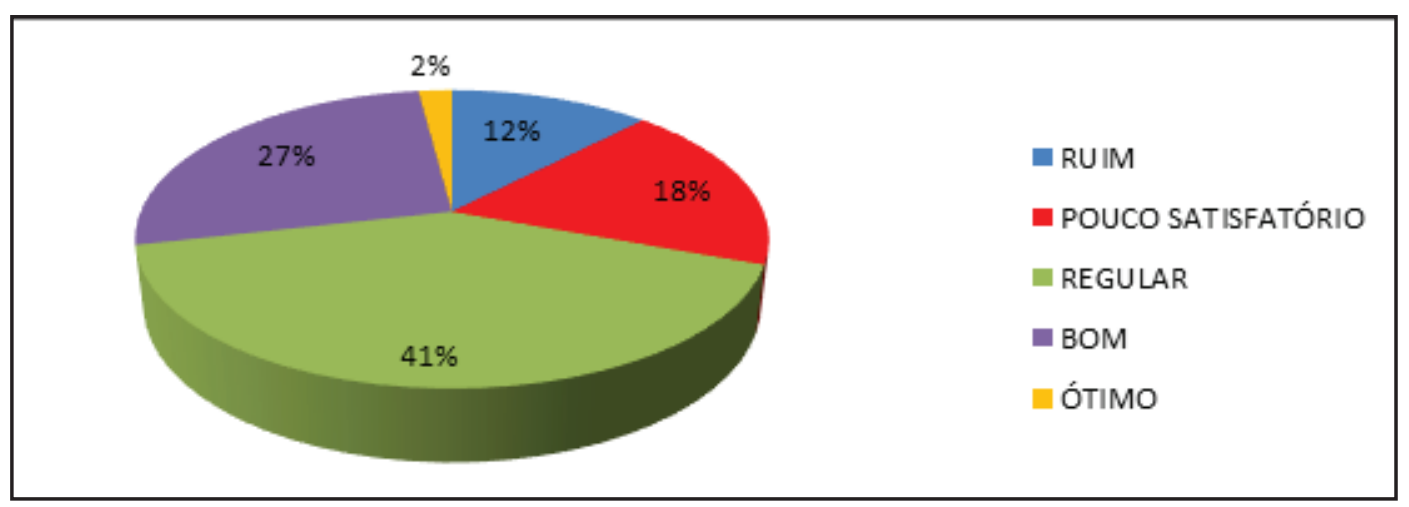

Figura 7: Servidores - Quantidade de pessoal em relação às necessidades do serviço. Fonte: Dados da pesquisa (2017)

A pergunta: Como você acha que a quantidade de pessoal na SEDEC em relação às necessidades do serviço está? Verifica-se divergência significativa nos percentuais, pois $29 \%$ afirmam ser suficientes ( $27 \%$ bom e $2 \%$ ótimo), $30 \%$ insuficiente ( $12 \%$ ruim e $18 \%$ pouco satisfatório) e os outros $41 \%$ regular. 


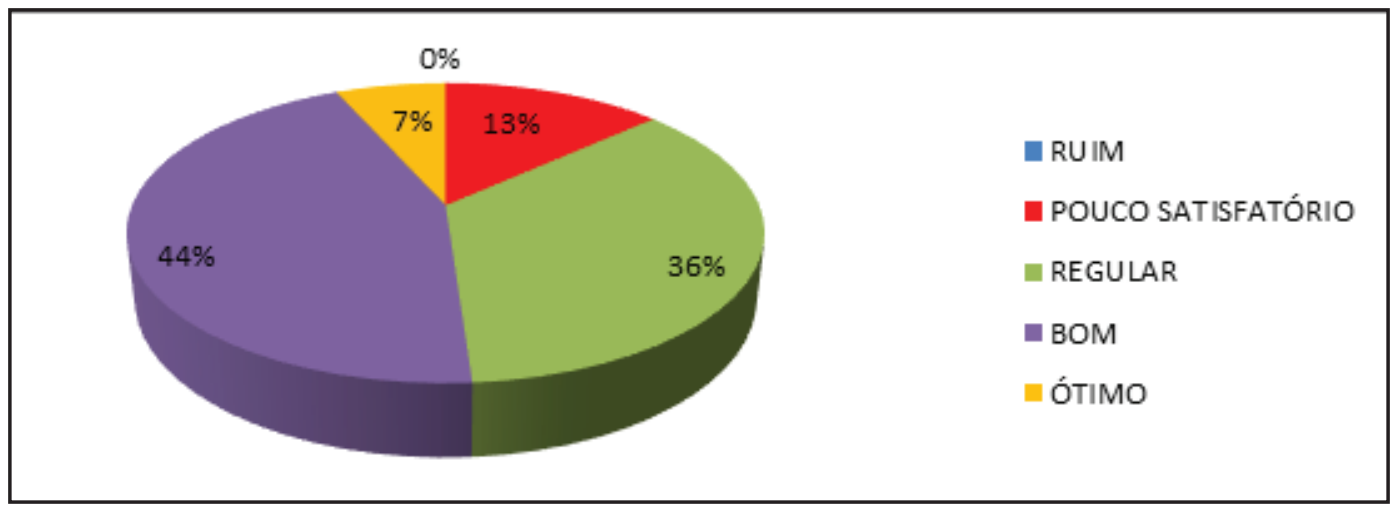

Figura 8: Demais respondentes - Quantidade de pesso-

al em relação às necessidades do serviço.

Fonte: Dados da pesquisa (2017)

No entanto, as respostas apresentadas pelos ocupantes dos demais cargos foram: $51 \%$ afirmam ser suficientes (44\% bom e $7 \%$ ótimo), $13 \%$ insuficiente $(0 \%$ ruim e $13 \%$ pouco satisfatório) e os outros $36 \%$ regular.

Vale ressaltar, por se tratar de uma organização pública o preenchimento de cargo ocorre por concurso público, processo seletivo e nomeação de cargos comissionados, porém todos de acordo com quantitativos aprovados em lei, portanto alteração no lotacionograma deve ser estudada a viabilidade. Mas, nada impede que a gestão faça um levantamento das necessidades e busque medidas para solucionar o problema, com objetivo de evitar a sobrecarga de trabalho ou até mesmo comprometer as atividades, afetando o ambiente de trabalho.

Quando questionados sobre as condições físicas do ambiente de trabalho quanto à ventilação, as respostas foram: $27 \%$ ruim, 24\% pouco satisfatório, $27 \%$ regular, 20\% bom e $2 \%$ ótimo, importante destacar que $51 \%$ dos servidores não estão satisfeitos com a ventilação do ambiente de trabalho.

Ao questionar os ocupantes dos demais cargos sobre as condições físicas do ambiente de trabalho quanto à ventilação, as respostas foram: 33\% ruim, 16\% pouco satisfatório, $24 \%$ regular, $22 \%$ bom e $5 \%$ ótimo.

Apesar de não haver um consenso nas respostas, o quantitativo de insatisfação é significativo para que organização verifique os motivos que levaram os servidores e os ocupantes dos demais cargos a terem esta opinião negativa da condição física do ambiente de trabalho e também quais as possíveis ações para dirimir essa situação. 


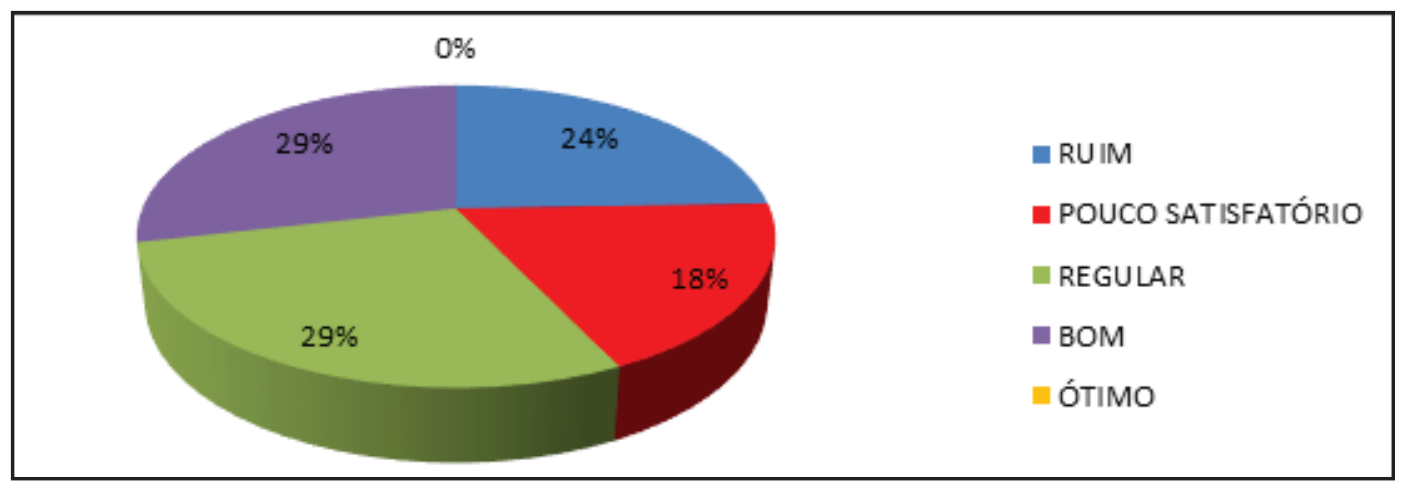

Figura 9: Servidores - Espaço adequado do ambiente de trabalho.

Fonte: Dados da pesquisa (2017)

Sobre condições de trabalho, foi indagado ainda sobre o espaço estar adequado, sendo a resposta de $24 \%$ ruim, $18 \%$ pouco satisfatório, 29\% regular e $29 \%$ bom, há uma parcela considerável de $42 \%$ dos servidores que não consideram o espaço adequado para desenvolverem suas atividades.

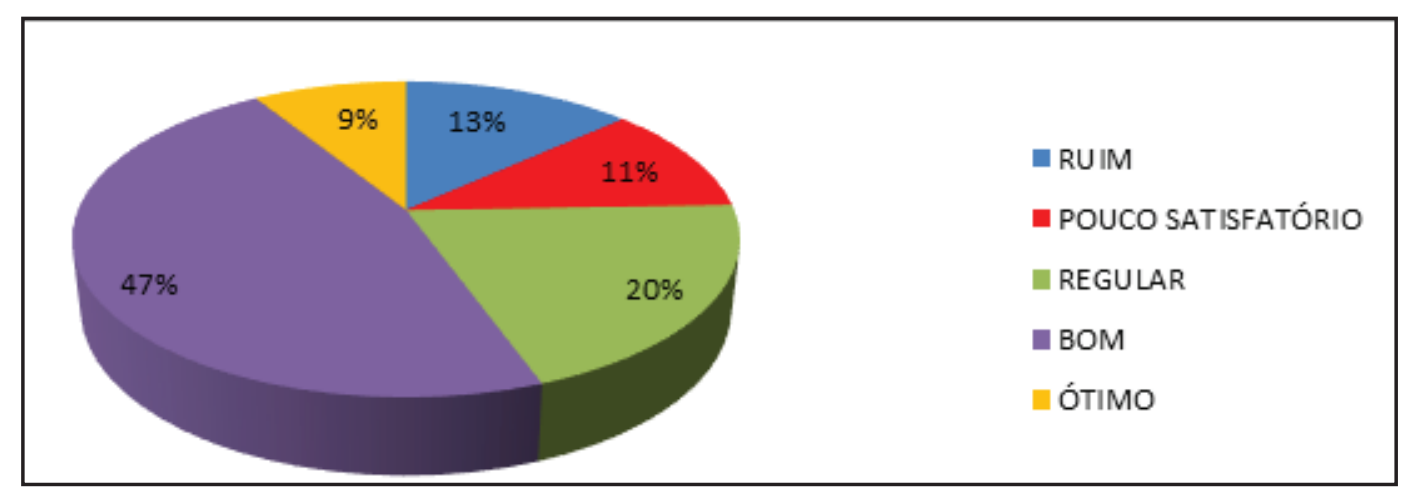

Figura 10: Demais respondentes - Espaço adequado do ambiente de trabalho. Fonte: Dados da pesquisa (2017)

A mesma pergunta foi feita para os ocupantes dos demais cargos, as respostas foram $13 \%$ ruim, $11 \%$ pouco satisfatório, $20 \%$ regular e $47 \%$ bom, $9 \%$ ótimo e $56 \%$ dos ocupantes dos demais cargos consideram o espaço da SEDEC adequado para desenvolverem suas atividades.

Rizzatti (1995) defende que as condições de trabalho proporcionam um ambiente organizacional favorável para desenvolver as atividades, com alto nível de rendimento dos funcionários e possibilitando atender algumas de suas necessidades.

Em análise as respostas observou-se que 51\% dos servidores e 49\% dos ocupantes dos demais cargos não estão satisfeitos com a ventilação. Apesar da divergência quanto ao espaço de trabalho, quando os servidores (29\%) consideram o ambiente adequado e $42 \%$ inadequado, por outro lado $56 \%$ dos ocupantes dos demais cargos consideram o espaço de trabalho adequado. É importante a gestão monitorar este fator, uma vez que poderá comprometer o rendimento dos servidores e tornar o ambiente de trabalho desfavorável. 
O quarto fator abordado é o relacionamento interpessoal, na pergunta: Como você classificaria o nível de companheirismo e integração na SEDEC? A maioria dos servidores responderam positivamente, $61 \%$ bom e $2 \%$ ótimo, seguido de $29 \%$ regular, $6 \%$ pouco satisfatório e $2 \%$ ruim. De acordo com as respostas o nível de companheirismo e integração na SEDEC é favorável.

Os ocupantes dos demais cargos responderam $56 \%$ bom, 16\% ótimo, 15\% regular, $9 \%$ pouco satisfatório e $4 \%$ ruim, representa um resultado positivo que influencia um ambiente de harmonia na organização.

Ainda sobre o fator relacionamento interpessoal, em resposta à pergunta: Em seu setor, as pessoas tendem reconhecer a competência profissional dos colegas? Das respostas apresentadas pelos servidores a maioria, $65 \%$ ( $43 \%$ frequentemente e $22 \%$ sempre), concordam que as pessoas reconhecem as competências profissionais dos colegas.

As respostas dos ocupantes dos demais cargos também a maioria dos respondentes $62 \%$, sendo $51 \%$ frequentemente e $11 \%$ sempre, afirmam que as pessoas reconhecem as competências profissionais dos colegas.

Esse reconhecimento é fruto da interação na relação de trabalho, onde um depende do outro para desenvolver suas atividades e gerando reciprocidade. Surgindo sentimentos que influenciam nos processos mentais e emocionais, que só são percebidos por pessoas que desfrutam da mesma interação, proporcionando uma relação harmoniosa entre as pessoas, como menciona Rizzatti (1995).

Deste modo pode-se dizer que os servidores e os ocupantes dos demais cargos da SEDEC possuem o fator de relacionamento interpessoal satisfatório, influenciando na harmonia do ambiente de trabalho, onde há interação, colaboração, reconhecimento e respeito.

O quinto fator abordado é sucessão político-administrativa e comportamento de chefias.



Figura 11: Servidores - O preparo dos cargos de chefia para a função.

Fonte: Dados da pesquisa (2017)

Ao indagar os servidores: Na sua opinião, as pessoas que ocupam cargos de chefia na SEDEC estão preparadas para essa função? Como demonstrado na Figura 11, somente $22 \%$ afirmaram que os chefes possuem competência suficiente para desempenhar as funções 
atribuídas ao cargo. Dos 49 servidores que participaram da pesquisa, 55\% acreditam que o preparo das pessoas para assumir a função é razoável e $23 \%$ afirmam que o preparo é pouco.

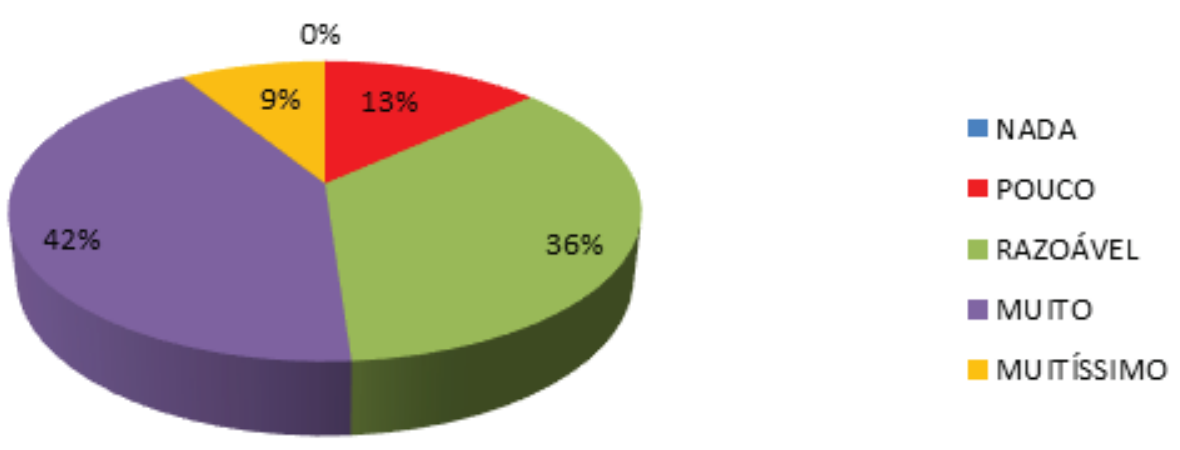

Figura 12: Demais respondentes - $O$ preparo dos cargos de chefia para a função.

Fonte: Dados da pesquisa (2017)

A opinião dos ocupantes dos demais cargos diverge da visão dos servidores, sendo que para $42 \%$ as pessoas são muito preparadas e $9 \%$ consideram muitíssimo preparadas, $36 \%$ razoavelmente preparadas e $13 \%$ pouco preparadas. A organização deve averiguar os motivos que levou a divergência nas respostas apresentadas.

Nota-se que os cargos de chefia, que desempenham papel de liderança, devem se preparar para assumir as atribuições e responsabilidades do cargo, pois como menciona Rizzatti (1995) os chefes precisam ser dotados de algumas características, como noção das funções gerais da instituição, inteligência, qualidades morais, lealdade, decisão, capacidade de delegar, capacidade de cooperar, entre outras.

Ainda sobre comportamento da chefia, perguntou-se: A sua chefia estimula e incentiva para o seu aperfeiçoamento profissional? As respostas dos servidores foram $27 \%$ sempre, $14 \%$ frequentemente, $31 \%$ poucas vezes, $18 \%$ às vezes e $10 \%$ nunca, não havendo conformidade nas respostas, o que deve ser averiguado pela organização, pois manter os servidores capacitados nas suas áreas de atuação contribui para o bom andamento da organização, além de favorecer o clima organizacional.

Por outro lado, as respostas dos ocupantes dos demais cargos foram $42 \%$ frequentemente, $20 \%$ sempre, $16 \%$ às vezes, $20 \%$ poucas vezes e $2 \%$ nunca, ou seja, mais de $50 \%$ dos respondentes afirmaram que a chefia incentiva para que se aprimorem na profissão, o que é um ponto positivo, pois mantem as pessoas satisfeitas com a organização.

O sexto e último fator proposto pelo modelo de Rizzatti (1995) é satisfação pessoal. 




Figura 13: Servidores - Salário é estimulante.

Fonte: Dados da pesquisa (2017)

Quanto à pergunta: Considerando as atividades que você exerce e as condições oferecidas pela SEDEC, o seu salário é estimulante? Dos servidores $43 \%$ responderam que o salário é estimulante, $43 \%$ que é razoável e $14 \%$ pouco estimulante.

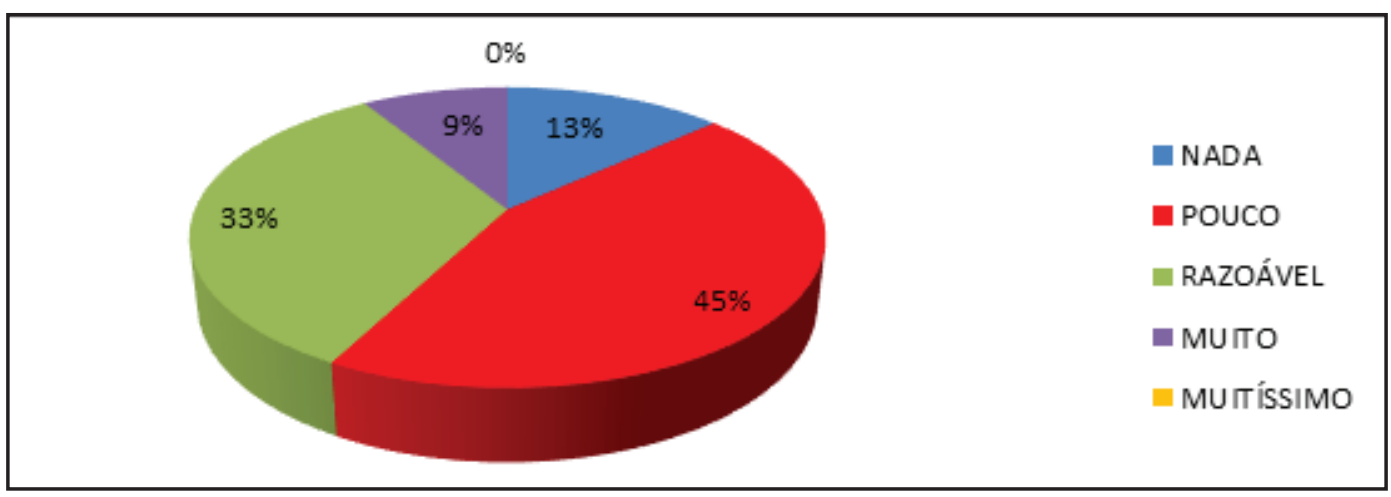

Figura 14: Demais respondentes - Salário é estimulante.

Fonte: Dados da pesquisa (2017)

Quanto à resposta dos ocupantes dos demais cargos a mesma pergunta, 9\% responderam que o salário é estimulante, $33 \%$ que é razoável, $45 \%$ pouco e $13 \%$ nada estimulante.

Nota-se que há divergência nas respostas e ressalta-se que por se tratar de uma organização pública existem planos de cargos, carreiras e salários que determinam os salários, sendo qualquer alteração somente possível por meio de aprovação legislativa.

Rizzatti (1995) destaca que o reconhecimento ou recompensa é aquele que o indivíduo julga ser compatível com seu nível de esforço, por isso a importância de investigar o motivo que leva uma parcela considerável dos ocupantes dos demais cargos não estar satisfeita com os seus salários, uma vez que esse descontentamento pode refletir no desempenho das atividades e prejudicar o clima organizacional.

Ainda sobre o fator satisfação pessoal, foi indagado: Você está satisfeito com o trabalho que executa? A maioria, representada por $63 \%$ dos servidores estão satisfeitos, 33\% 
razoavelmente satisfeitos e $4 \%$ não estão satisfeitos. Os ocupantes dos demais cargos responderam de modo semelhante, sendo $69 \%$ satisfeitos, $24 \%$ razoavelmente e $7 \%$ nada satisfeito.

Rizzatti (1995) explica que satisfação pessoal se refere ao quanto o trabalhador está contente com as atividades que exerce e o reconhecimento que recebe por parte da organização. Por isso, manter os funcionários estimulados e satisfeitos é um trabalho contínuo e que influencia o clima organizacional.

\subsection{Algumas proposições de ações}

Com base na análise e discussão dos dados podem-se elencar algumas proposições de ações para mitigar os pontos negativos e sugerir melhorias para manter favorável o clima organizacional da SEDEC, como:

- Melhorar a política de recursos humanos, implantando ações de valorização dos servidores pelo seu desempenho profissional;

- Fazer um estudo de redistribuição de pessoal de acordo com a necessidade de cada setor;

- Melhorar as condições físicas do ambiente de trabalho quanto à ventilação e espaço adequado para os servidores e ocupantes dos demais cargos desenvolverem as atividades com satisfação;

- Elaborar um plano de treinamento e desenvolvimento de liderança, para que as pessoas que estão nos cargos de chefia possam desempenhar melhor suas atribuições, considerando o número representativo de cargos em comissão;

- Implementar programas de qualidade de vida para compensar a insatisfação com a remuneração;

- Desenvolver programas de capacitação contínua (de acordo com as necessidades dos setores e dos funcionários);

- Criar um canal de comunicação, no qual os funcionários possam encaminhar suas críticas e sugestões para solucionar problemas, contribuindo para melhoria dos serviços prestados pela organização;

- Realizar periodicamente pesquisa de clima organizacional para identificar os pontos de melhorias e os pontos fortes da organização, com intuito de manter a harmonia no ambiente de trabalho.

Cabe ao Gestor da Secretaria avaliar a viabilidade e os benefícios das proposições apresentadas. Em seguida apresentam-se as considerações finais.

\section{CONSIDERAÇÕES FINAIS}

$\mathrm{O}$ presente estudo teve como objetivo geral analisar os fatores que influenciam o clima organizacional no ambiente de trabalho da SEDEC. Para isso, identificaram-se os fatores que influenciam positivamente ou negativamente o clima organizacional da Secreta- 
ria; verificou-se que o clima organizacional se encontra desfavorável com base no modelo de Rizzatti (1995), propuseram-se ações para mitigar os pontos negativos, além de sugerir ações para melhorar o clima organizacional da Secretaria.

$\mathrm{O}$ estudo teve o intuito de responder a questão norteadora: Quais os fatores que influenciam o Clima Organizacional da Secretaria de Estado de Desenvolvimento Econômico (SEDEC/MT)? Os fatores que influenciaram para proporcionar um clima organizacional desfavorável na Secretaria são: a imagem e avaliação da SEDEC onde se verificou que uma parcela dos servidores não sente orgulho de trabalhar na organização;

O fator que pode estar influenciando para desarmonizar o ambiente de trabalho é o desenvolvimento de recursos humanos, benefícios e incentivos, tendo um percentual significativo de ocupantes dos demais cargos que consideraram a remuneração incompatível com as atividades que desempenham, além de servidores que não se sentem valorizados pela política de recursos humanos.

Outro fator preocupante é a organização e condições de trabalho, sendo que uma parcela dos servidores acredita que o quantitativo de pessoal é insuficiente. Tanto os servidores quanto os ocupantes dos demais cargos opinaram negativamente sobre as condições físicas de ventilação. Referente o espaço físico um percentual de servidores considera inadequado e não houve consenso na avaliação dos ocupantes dos demais cargos.

O fator sucessão político-administrativa e comportamento de chefias são desfavoráveis, apesar dos ocupantes dos demais cargos terem respondido que o preparo dos chefes para desempenharem as funções é satisfatório e que há estímulo das chefias para aperfeiçoamento profissional, por outro lado os servidores não acreditam que os chefes estão preparados para as funções.

Quanto à satisfação pessoal, os ocupantes dos demais cargos consideraram que o salário é desestimulante, o que pode contribuir para um clima organizacional desarmônico, mesmo que a maioria dos respondentes sente-se satisfeita na atividade que desenvolve na Secretaria.

O fator relacionamento interpessoal foi o único favorável, constatou-se nas respostas apresentadas pelos servidores e ocupantes dos demais cargos que no ambiente existe cooperação, colaboração, respeito e reconhecimento entre os colegas de trabalho.

Por isso, com intuito de conseguir e manter um ambiente de trabalho harmonioso foram propostas algumas ações visando mitigar os pontos negativos e sugestões de melhorias para o clima organizacional da Secretaria.

Como fator limitador, a Secretaria tem funcionários lotados em dois prédios em endereços distintos, o que prejudicou na coleta de dados, pois os funcionários lotados na Secretaria Adjunta de Turismo não aderiram conforme o previsto, deste modo afetou a amostra da pesquisa. Outro fator limitador foi a não estratificação dos resultados por setores.

Por fim, como sugestão para os próximos estudos, propõe-se que seja realizada uma entrevista com o Gestor da Secretaria para analisar sua percepção do clima organizacional da SEDEC, já que neste trabalho não foi possível. Bem como fazer uma pesquisa com o 
público atendido pela Secretaria para analisar qual o reflexo do clima organizacional no atendimento dos beneficiários/usuários dos serviços prestados pela Secretaria.

\section{REFERÊNCIAS}

BARTHASAR, M. T. M. Clima organizacional: um estudo empírico com as guardas civis municipais da região do ABC. Dissertação (Mestrado em Administração) - Programa de Pós-Graduação em Administração, Universidade Municipal de São Caetano do Sul, São Caetano do Sul, 2014.

BENNIS, W. A formação do líder. São Paulo: Atlas, 162 p, 1996.

BEZERRA, S.A. Apostila de cálculo do tamanho de amostras. Toledo: Unipar, 2003.

BISPO, C. A. F. Um novo modelo de pesquisa de clima organizacional. Produção, EESC - USP, v.16, n.2, p.258-273, maio/ago. 2006.

CODA, R. Estudo sobre clima organizacional traz contribuição para aperfeiçoamento de pesquisa na área de RH. In: Boletim Administração em Pauta, suplemento da Revista de Administração, São Paulo. IA-USP, n. 75, dez., 1993.

CURVO, L. D.; HEINZMANN, L. M. Estudo do clima organizacional da Secretaria de Gestão de Pessoas de uma Universidade Federal. RECC Revista Eletrônica Científica do CRA-PR. v. 4, n. 1, p. 1-18, 2017.

KOLB, D. A. et al. Psicologia organizacional: uma abordagem vivencial. São Paulo: Atlas, 1986.

KRUMM, D. J. Psicologia do trabalho: uma introdução à psicologia industrial/organizacional. Rio de Janeiro: LTC, 2013.

HEINZMANN, L. M.; SILVA, M. G. Análise do clima organizacional da Junta Comercial do Estado de Mato Grosso. ReFAE Revista da Faculdade de Administração e Economia. v. 6, n. 1, p. 147$169,2014$.

LAKATOS, E. M.; MARCONI, M. A. Fundamentos de metodologia científica. $5^{\circ}$ Ed. São Paulo: Atlas, 2007.

LUZ, R. Clima organizacional. Rio de Janeiro: Qualitymark, 1995.

LUZ, R. Gestão do clima organizacional. Rio de Janeiro: Qualitymark, 2003.

MARTINS, M. C. F. Clima organizacional. In. SIQUEIRA, M. M. M. (Org.) Medidas do comportamento organizacional: ferramentas de diagnóstico e de gestão. Porto Alegre, Artmed, 2008. p. $29-40$.

RIZZATTI, G. Análise de fatores significativos do clima organizacional da Universidade Federal de Santa Catarina: contribuição para implantação do programa de qualidade. Dissertação (Mestrado em Administração) - Curso de Pós-Graduação em Administração, Universidade Federal de Santa Catarina, Florianópolis, 1995.

RIZZATTI, G. Categorias de análise de clima organizacional em universidades federais brasileiras. Tese (Doutorado em Engenharia da Produção) - Programa de Pós-Graduação em Engenharia de Produção, Universidade Federal de Santa Catarina, Florianópolis, 2002.

ROCHA, A. C.; CERETTA, G. F.; LIMA, J. A. de. Clima organizacional em hospital: um estudo no sudoeste do Paraná. Revista REUNA. Belo Horizonte, MG. v. 19, n. 2, p. 71-90, 2014.

SANCHES, J. P.; CASTRO, A. L. de. Relação entre a percepção do clima organizacional e o comportamento organizacional positivo: estudo no setor de obras da Prefeitura de Tamboara-PR. REUNIR Revista de Administração, Contabilidade e Sustentabilidade. v. 5, n. 3, p/ 19-38, 2015. 
SCHEIN, E. H. Organizational culture and leadership. São Francisco: Jossey-Bass, 1985.

SOUZA, E. L. P. Clima e motivação em uma empresa estatal. Revista de Administração de Empresas. Rio de Janeiro, v. 22, n. 1, p. 18, 1982.

ZANELLI, J. C. BORGES-ANDRADE, J. E. BASTOS, A. V. B. Psicologia, organizações e trabalho no Brasil. Porto Alegre: Artmed, 2004.

YIN, R. K. Estudo de caso: planejamento e métodos I Robert K. Yin; trad. Daniel Grassi- 2.ed.Porto Alegre: Bookman, 2001.

VILLARDI, B. Q.; FERRAZ, V. N.; DUBEUX, V. J. C. Uma metodologia para diagnóstico de clima organizacional: integrando motivos sociais e cultura brasileira com fatores do ambiente de trabalho do Poder Judiciário. Revista de Administração Pública, FGV. Rio de Janeiro, v. 45, n. 2, p. 303329, mar./abr. 2011.

Submetido em: 18-2-2019

Aceito em: 12-7-2021 